\title{
Shape memory and mechanical properties of polycaprolactone/polypropylene carbonate nanocomposite blends in the presence of G-POSS nanoparticles
}

\author{
A. Kamyab ${ }^{1}$, A. Ghasemi-Ghalebahman ${ }^{1}$, A. Fereidoon ${ }^{1}$, H. A. Khonakdar ${ }^{2}$ \\ ${ }^{1}$ Faculty of Mechanical Engineering, Semnan University, Semnan, Iran \\ ${ }^{2}$ Leibniz Institute of Polymer Research, D-01067 Dresden, Germany
}

Received 13 August 2020; accepted in revised form 7 November 2020

\begin{abstract}
This study deals with investigating the morphological, mechanical, dynamic-mechanical, and shape memory properties of novel Polycaprolactone (PCL)/polypropylene carbonate (PPC)-based nanocomposite blends reinforced with GlycidylIsobutyl-functionalized polyhedral oligomeric silsesquioxane (G-POSS) nanoparticles. Scanning Electron Microscopy images of blends revealed droplet-matrix morphology with distinct domains where increased PPC content led to increased number and size for PCC droplets. Introducing nanoparticles by compatibilizing the blends changed the droplet-matrix morphology to a co-continuous one and consequently improved mechanical and shape memory properties. Distribution of nanoparticles up to $5 \mathrm{wt} \%$ remained uniform for samples with higher PPC contents. The shape memory analysis results revealed that the shape memory properties were highly dependent on the mixing ratio of polymers and nanoparticles content. Besides, introducing the nanoparticles caused a considerable reduction in the recovery time. Finally, the composition with a PCL/PPC ratio of 20/80 as well $5 \mathrm{wt} \%$ G-POSS content was suggested as the sample with optimum shape memory properties with $T_{\mathrm{g}}=35^{\circ} \mathrm{C}$, fixity ratio $=98 \%$, recovery ratio $=95 \%$, and the remarkable recovery time of 17 seconds, enjoying the elastic modulus of $772 \mathrm{MPa}$, the tensile strength of $85.2 \mathrm{MPa}$, and elongation at break of $450 \%$ that shows the high potential of this blend for different applications, especially in the biomedical field.
\end{abstract}

Keywords: nanocomposites, polycaprolactone, polypropylene carbonate, POSS, shape memory

\section{Introduction}

Shape memory polymers (SMPs) have always enjoyed a great interest between shape-memory materials due to properties such as high recovery strain, desired processability, biocompatibility, low preparation costs, and programmable glass transition temperature $\left(T_{\mathrm{g}}\right)$ [1]. Despite the advantages of SMPs for diverse biomedical applications, they do not possess good mechanical properties [2]. The mechanical properties of SMPs could be improved using methods such as blending with a polymer with higher mechanical properties and preparing polymeric blends, preparing shape memory polymer composites (SMPCs) by adding nanoparticles, or using both methods. The shape memory effect is bestowed to polymers through physical or chemical cross-links. These cross-links are either intrinsic or are introduced or improved through processes such as synthesizing, blending with other polymers, or adding nanoparticles [3]. Compared to performing synthesis, mixing is a more effective method to prepare SMPs for more feasible processability [4]. These cross-links are formed in SMPs through permanent components (PC) responsible for memorizing the initial shape and the switching components (SC) that are responsible for retaining the temporary shape [3]. In shape memory blends, 
the $T_{\mathrm{g}}$ of the component that plays the role of SC in that temperature range determines the $T_{\mathrm{g}}$ of the blend. Polymers and nanocomposites used in SMPCs for biomedical applications need to be biocompatible. Polyglycolic acid (PGA), poly l-lactic acid (PLLA), polylactic acid (PLA), polycaprolactone (PCL), polyhydroxyalkanoates (PHAs), and polypropylene carbonate (PPC) are among these biocompatible polymers [5-11]. The effect of incorporating biocompatible nanoparticles such as silica, colloid gold, $\mathrm{TiO}_{2}$ nanoparticles, gold nanoparticles, and polyhedral oligomeric silsesquioxane (POSS) on morphological, thermal, mechanical, and shape memory properties of some of the blends of these polymers are previously studied [12-18]. One of the problems facing the researchers is the immiscibility of polymers in blends, which sometimes lead to phase separation and, as a result, the loss in mechanical and shape memory properties of blends. One of the methods of solving this problem is adding nanoparticles to improve the compatibility and miscibility of the two polymers [2]. When the distribution of nanoparticles in the polymeric blend is favorable, and nanoparticles lead to increased compatibility between two polymers at the interface of two immiscible polymers, the shape memory properties could be enhanced along with the mechanical properties [19-21].

Between biocompatible polymers, PCL, which is a semicrystalline SMP with a $T_{\mathrm{g}}$ of about $-60^{\circ} \mathrm{C}$, melting temperature of about $60^{\circ} \mathrm{C}$, the elastic modulus of 200-400 MPa, high processability, low toxicity, hydrophilicity, and high strain at break that has been studied for biomedical applications such as drug delivery, sutures, stents, and tissue engineering [5, 2227]. This polymer has been researched blended with materials such as PLA, PPC, polymethyl vinyl siloxane (PMPS), Epoxidized Natural Rubber, PVS, and polyethylene glycol [10, 28-33]. For instance, Liu et al. [27] blended PCL and PVS that are miscible and prepared a blend with the triple-shape-memory property. They reported that the crystalline domains of PCL, as well as physical constraints, acted as the $\mathrm{PC}$ and the amorphous PVC, and the amorphous domains of PCL acted as the SC in high and low switch temperatures, respectively. For PCL and bisphenol Abased polybenzoxazine (PBA-a) blends, Schäfer et al. [34] reported that free PCL tended to phase separate, which led to discontinuous phases in the blend. A lower crystallinity due to the absence of free PCL led to a less stabilized network and, accordingly, to a lower material stiffness. PCL has also been blended with epoxy with a bio-based curing agent, viz. cashew nut shell liquid as bio-related smart materials, and it was observed that an increase in the PCL content up to $20 \mathrm{wt} \%$ considerably improved the shape memory response [35]. Accordingly, this polymer was chosen as one of the components of the polymer blend for the current study.

Nonetheless, PCL does not enjoy high mechanical properties and has a $T_{\mathrm{g}}$ of $-60^{\circ} \mathrm{C}$. For the prepared blends to have an operational shape memory effect for biomedical applications, the transition temperature of their SC needs to be between room temperature and physiological temperature and higher mechanical properties compared to PCL to improve the mechanical properties of PCL. In this study, PPC, which is an amorphous polymer with a $T_{\mathrm{g}}$ in the $35^{\circ} \mathrm{C}$ range, the elastic modulus of $700-800 \mathrm{MPa}$, and elongation at break of 500-600\%, was chosen as the SC [36]. PCL/PPC blends are previously studied by Zheng et al. [50], and it was reported that they had a high recovery and shape fixity ratio at about $35^{\circ} \mathrm{C}$. They concluded that in the blends based on these two polymers, semicrystalline PCL played the role of PC and PPC played the role of SC. Since this blend was proved to be biocompatible, stent samples based on the optimum composition of PCL25/PPC75 were prepared that showed a short recovery time of about 25 seconds. Nevertheless, the properties of these polymers have not been reported in the presence of nanoparticles.

Preparing nanocomposites containing biocompatible POSS particles and their functionalized types, as well as investigating their properties, have been of interest to many researchers [37-40]. PCL/POSS SMPCs are previously investigated, and an improved property for PCL is reported in the presence of the functionalized types of this nanoparticle [24, 41-45]. Nonetheless, the transition temperature of these SMPCs is in the $60^{\circ} \mathrm{C}$ range, which renders their shape memory property inapplicable for biomedical applications [38, 43-45]. It should also be mentioned that, according to the literature, functionalized POSS nanoparticles are capable of improving the recovery time [46]. Therefore, to prepare the SMPCs, POSS nanoparticles functionalized with GlycidylIsobutyl (G-POSS) was chosen to be added to the PCL/PPC blends between available biocompatible nanoparticles, which has been investigated in many pieces of recent studies in which cage-like molecular structure 


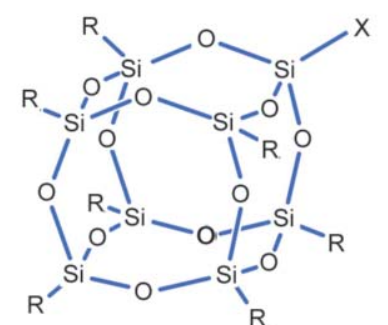

a)

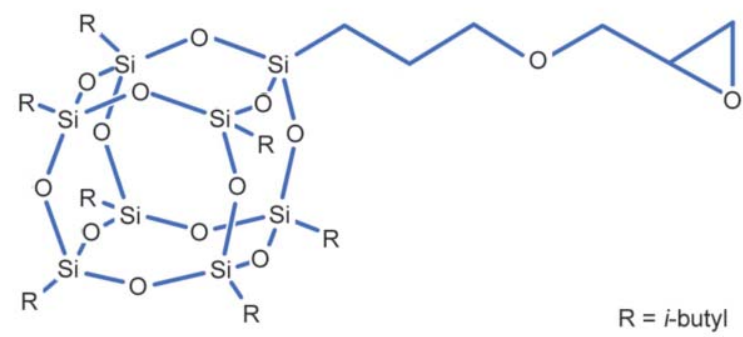

b)

Figure 1. The molecular structures of (a) POSS and (b) G-POSS.

is present that comprises silicone-oxygen frame linked to organic groups, which make them compatible with polymers, as well as an organic-nonorganic hybrid [47]. Figure 1 depicts the molecular structures of POSS and G-POSS, with particle sizes of approximately $2-5 \mathrm{~nm}$.

This study aimed to evaluate the effects of incorporating G-POSS nanoparticles into PCL/PPC blends on the morphology, mechanical properties, mechanical-dynamic properties, and shape memory properties as these compounds seem to be of high potential for biomedical applications [48]. Since PCL/PPC blends are not miscible, an agent that could improve the compatibility of their blends concerning the chemical structure of both polymers and said agent could be favorable [49]. No report of any nanoparticles added to PCL/PPC blends is found in the literature. Moreover, according to the mechanical properties of blends studied in past pieces of research, the shape memory properties, fast recoverability, biocompatibility, and the temperature range where these blends could be utilized [50], the likely positive effects of G-POSS nanoparticles on these properties were investigated, and the sample with most desired shape memory properties was suggested. Finally, according to the results obtained from the analysis, a suitable candidate for further investigations for medical applications will be suggested.

\section{Experimental details}

\subsection{Materials and methods}

PCL $\left(M_{\mathrm{n}}: 80000 \mathrm{~g} / \mathrm{mol}\right)$ was obtained from Sigma Aldrich, Taufkirchen, Germany, in granular form. It had a density of $1.145 \mathrm{~g} / \mathrm{ml}$, a melt flow index 2.01$4.03(\mathrm{~g} / 10 \mathrm{~min})\left(160^{\circ} \mathrm{C} / 5 \mathrm{~kg}\right)$, as well as glass transition and melting temperatures of $-60^{\circ} \mathrm{C}$ and 58 $60^{\circ} \mathrm{C}$, respectively. PPC (MFCD00197919, $M_{\mathrm{n}}$ : $50000 \mathrm{~g} / \mathrm{mol}$ ) was also purchased in granular form from Sigma Aldrich, Taufkirchen, Germany. It had a density of $1.24 \mathrm{~g} / \mathrm{ml}$, as well as glass transition and melting temperatures of $25-40^{\circ} \mathrm{C}$ and $58-60^{\circ} \mathrm{C}$, respectively. Glycidyllsobutyl POSS (G-POSS) was purchased from Hybrid Plastics, Hattiesburg, USA (product \#: EP0418). It had a density of $1.14 \mathrm{~g} / \mathrm{ml}$ and a refractive index of 1.47. All chemicals were used as received without further purification.

PCL and PPC pellets were dried in an oven at $40^{\circ} \mathrm{C}$ for 12 hours. Then, the weight ratios of PCL100/PPC0, PCL80/PPC20, PCL60/PPC40, PCL40/PPC60, PCL20/PPC80, and PCL0/PPC100 of the polymers were measured, and the compounds were subjected to melt blending in an internal mixer (Rheomix Haake, USA) at $150^{\circ} \mathrm{C}$ and $100 \mathrm{rad} / \mathrm{min}$ for $5 \mathrm{~min}$. After subtracting the intended weight ratios of nanoparticles, the G-POSS weight fractions of 1,3 , and $5 \%$ were added. The process continued for $3 \mathrm{~min}$. The resulted melt was taken out and cooled in the form of pellets. All blends were given the same processing treatment. Prepared blends were again dried at $40^{\circ} \mathrm{C}$ in a vacuum oven for 12 hours before further processing. Table 1 shows weight fractions and codings. Accordingly, the first number in each code shows the PCL content, the second one shows the PPC content, and the last number shows the G-POSS content. For instance, the PL10-PC0-GP0 sample has a $100 \mathrm{wt} \%$ PCL content and $0 \mathrm{wt} \%$ PPC and G-POSS content, and the PL2-PC8-GP5 sample has a $20 \mathrm{wt} \%$ PCL content, an $80 \mathrm{wt} \%$ PPC content, as well as $5 \mathrm{wt} \%$ G-POSS content.

The produced pellets were subjected to compression moulding at $150^{\circ} \mathrm{C}$ for $5 \mathrm{~min}$. Dumbbell-shaped specimens with a thickness of $1 \mathrm{~mm}$ were fabricated for tensile and shape memory tests in accordance with ASTM D638 Standard. Rectangular samples with dimensions of $50 \mathrm{~mm} \times 5 \mathrm{~mm} \times 0.5 \mathrm{~mm}$ were produced for DMA tests. Since PPC absorbs moisture, the PPC-containing specimens were kept in a glass container exposed to silica gel as a desiccant before they were tested. 
Table 1. The codings of the specimens and respective weight fractions.

\begin{tabular}{|l|c|c|c|}
\hline \multicolumn{1}{|c|}{ Sample code } & $\begin{array}{c}\text { PCL } \\
\text { [wt } \% \mathbf{]}\end{array}$ & $\begin{array}{c}\text { PPC } \\
\text { [wt } \% \mathbf{]}\end{array}$ & $\begin{array}{c}\text { G-POSS } \\
\text { [wt } \mathbf{0}]\end{array}$ \\
\hline PL10-PC0-GP0 & 100.0 & 0 & 0 \\
\hline PL10-PC0-GP1 & 99.0 & 0 & 1 \\
\hline PL10-PC0-GP3 & 97.0 & 0 & 3 \\
\hline PL10-PC0-GP5 & 95.0 & 0 & 5 \\
\hline PL8-PC2-GP0 & 80.0 & 20.0 & 0 \\
\hline PL8-PC2-GP1 & 79.2 & 19.8 & 1 \\
\hline PL8-PC2-GP3 & 77.6 & 19.4 & 3 \\
\hline PL8-PC2-GP5 & 76.0 & 19.0 & 5 \\
\hline PL6-PC4-GP0 & 60.0 & 40.0 & 0 \\
\hline PL6-PC4-GP1 & 59.4 & 39.6 & 1 \\
\hline PL6-PC4-GP3 & 58.2 & 38.8 & 3 \\
\hline PL6-PC4-GP5 & 57.0 & 38.0 & 5 \\
\hline PL4-PC6-GP0 & 40.0 & 60.0 & 0 \\
\hline PL4-PC6-GP1 & 39.6 & 59.4 & 1 \\
\hline PL4-PC6-GP3 & 38.8 & 58.2 & 3 \\
\hline PL4-PC6-GP5 & 38.0 & 57.0 & 5 \\
\hline PL2-PC8-GP0 & 20.0 & 80.0 & 0 \\
\hline PL2-PC8-GP1 & 19.8 & 79.2 & 1 \\
\hline PL2-PC8-GP3 & 19.4 & 77.6 & 3 \\
\hline PL2-PC8-GP5 & 19.0 & 76.0 & 5 \\
\hline PL0-PC10-GP0 & 0 & 100.0 & 0 \\
\hline PL0-PC10-GP1 & 0 & 99.0 & 1 \\
\hline PL0-PC10-GP3 & 0 & 97.0 & 3 \\
\hline PL0-PC10-GP5 & 0 & 95.0 & 5 \\
\hline
\end{tabular}

\subsection{Characterization}

In order to investigate the morphologies of the specimens, SEM images were recorded at $20 \mathrm{kV}$ by a TESCAN VEGA3 (Tescan, Fuveau, France) machine. Samples were broken in tension in liquid nitrogen to obtain cryogenically-fractured surfaces. The fracture surfaces of the specimens were sputter-coated with a $15 \mathrm{~nm}$ thick gold layer. Besides, to examine the dispersion quality and distribution locations of G-POSS nanoparticles within the blends, energy dispersive X-ray (EDX) mapping was carried out for (PL8PC2-GP5), (PL2-PC8-GP5) nanocomposites as representatives.

Static tensile tests were performed by a universal testing machine (SANTAM STM-50, Tehran, Iran) using dumbbell type specimens according to ASTM D638 type V with a $100 \mathrm{~N}$ load cell for evaluating Young's modulus, tensile strength, and elongation at break. The gauge length in all tests was set to $25 \mathrm{~mm}$, and the strain rate was $50 \mathrm{~mm} / \mathrm{min}$ until complete failure. In this study, engineering stress and engineering strain were used, and mechanical tests were conducted at room temperature. To estimate the strain, the relative crosshead movement was measured and then was divided by the gauge length.

The Young's modulus of each sample was determined by linearly fitting the elastic portion of the stress-strain curve before the yielding point (slope of the curve between 0 and $2 \%$ of deformation). The average values of Young's modulus, tensile strength, and elongation at break were determined from three test specimens, and an average of three values is reported.

To obtain the storage modulus $\left(E^{\prime}\right)$ and loss tangent $(\tan \delta)$ versus temperature curves, dynamic mechanical analysis (DMA) experiments were carried out in tensile mode with a dynamic mechanical thermal analyser (Mettler Toledo, DMA1, Columbus, USA) in tensile mode within the temperature range of -90 to $80^{\circ} \mathrm{C}$ at a heating rate of $3^{\circ} \mathrm{C} / \mathrm{min}$, a maximum amplitude of $200 \mu \mathrm{m}$ and constant frequency of $1 \mathrm{~Hz}$. Uniaxial shape memory tensile tests were performed using an INSTRON 6025 (Massachusetts, US) machine equipped with a heat chamber. Based on different mixing ratios, the DMA results showed that the glass transition temperature was about $35^{\circ} \mathrm{C}$ (between the room and body temperature). To apply shape memory cycles at a temperature of nearly $35^{\circ} \mathrm{C}$, the high-temperature $T_{\mathrm{h}}$, and the low-temperature $T_{1}$ above and below the glass transition temperature $T_{\mathrm{g}}$ were selected, respectively. These temperatures were chosen by a suitable difference of $15^{\circ} \mathrm{C}$, or in other words, $T_{1}=T_{\mathrm{g}}-15$ and $T_{\mathrm{h}}=T_{\mathrm{g}}+15$. Since uniform heating was required for samples, a heating program was applied to the temperature interval between $T_{1}$ and $T_{\mathrm{h}}$ such that the fixed heating and cooling rates of $3{ }^{\circ} \mathrm{C} / \mathrm{min}$ were applied to the specimens [51] (Figure 2). Four typical mechanical-thermal shape memory loading courses are described [52].

1) At $T_{\mathrm{h}}$ in the controlled-strain mode, $50 \%$ of elongation was applied to the samples at a rate of $50 \% / \mathrm{min}$ to $\varepsilon_{\mathrm{m}}$,

2) While keeping $\varepsilon m$ unchanged, the samples were cooled from $T_{\mathrm{h}}$ to $T_{1}$ at a rate of $3{ }^{\circ} \mathrm{C} / \mathrm{min}$ and were kept at $T_{1}$ for 10 min to obtain equilibrium (B-C); the increased stress arose from the increased elastic modulus due to crossing the $T_{\mathrm{g}}$,

3) The samples were unloaded to reach zero stress; therefore, a slight portion of $\varepsilon_{\mathrm{m}}$ was restored, and the temporary strain $\varepsilon_{\mathrm{f}}$ was recorded $(\mathrm{C}-\mathrm{D})$, and

4) The samples were heated at a rate of $3^{\circ} \mathrm{C} / \mathrm{min}$ to $T_{\mathrm{h}}$, while the stress and strain were recorded 


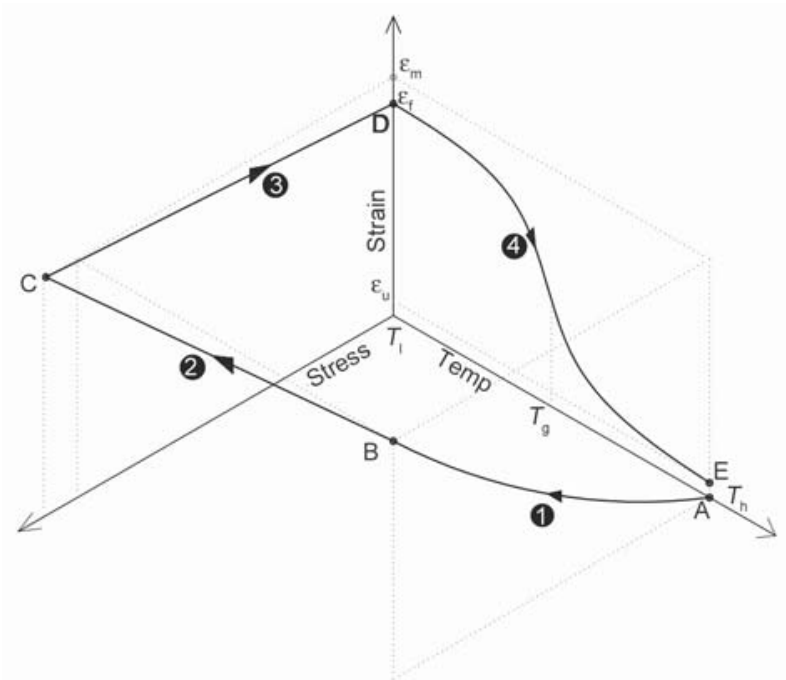

Figure 2. The schematic representation of a typical thermomechanical cycle for the shape memory polymers. A deformation of up to $50 \%$ was applied at the course (1) at a high temperature. Then, the sample was cooled at the course (2) at a fixed strain to maintain its temporary shape. The sample was disengaged at the course (3) to allow for free deformation. The original shape was restored at a freestress condition at the course (4).

every minute during this process until thermal equilibrium was reached at $T_{\mathrm{h}}(\mathrm{D}-\mathrm{E})$.

The shape recovery $R_{\mathrm{r}}$ and fixity $R_{\mathrm{f}}$ ratios were calculated as shown by Equations (1) and (2):

$R_{\mathrm{r}}=\frac{\varepsilon_{\mathrm{m}}-\varepsilon_{\mathrm{u}}}{\varepsilon_{\mathrm{m}}}$

$R_{\mathrm{f}}=\frac{\varepsilon_{\mathrm{f}}}{\varepsilon_{\mathrm{m}}}$

where $\varepsilon_{\mathrm{m}}$ is the applied strain at the high temprature, $\varepsilon_{\mathrm{u}}$ is the permanent strain after recovery, $\varepsilon_{\mathrm{f}}$ is the temporary strain after unloading.

\section{Results and discussion}

Since one of the purposes of this study was investigating the mixing behavior of the two polymers and the dispersion of the nanoparticles in the polymer matrix, for brevity, SEM images and EDX mappings of cryogenically-fractured surfaces of samples with codes shown in Figure 3 were prepared. It should be mentioned that for the sake of brevity, the figures related to pristine PCL and PPC samples are not shown here.

In the virgin blends (Figures $3 \mathrm{a}$ and $3 \mathrm{~b}$ ), the typical droplet-matrix morphology with distinct domains was observed, where increasing PPC content caused smoother fracture surfaces, droplet dimensions increased from $0.3-0.7 \mu \mathrm{m}$ in sample PL8-PC2-GP0 to $0.5-2 \mu \mathrm{m}$ in sample PL2-PC8-GP0, and they also increased in number. Hence, it could be concluded that for these blends, PPC played the role of droplets, and PCL played the role of the matrix [53]. Also, the distinct domains were suggestive of the immiscibility of these blends [54]. On the other hand, for immiscible blends, the polymer with higher viscosity plays the role of the droplet, and here, PPC is represented as such [55]. It was also observed that the PCL matrix well encompassed PPC droplets.

For the SEM images of the nanocomposites shown in Figures $3 \mathrm{c}$ and $3 \mathrm{~d}$, it was observed that an incremented G-POSS content reduced the sizes and enhanced the distribution of the PPC droplets to an extent where distinguishing the domain of phases was not facile. Incorporating more G-POSS content to $5 \%$ also bestowed a more proper distribution to the PPC phase so that in the micrographs related to the PL8-PC2-GP5 and PL2-PC8-GP5 samples, the droplet-matrix morphology transformed to the cocontinuous morphology (Figures $3 \mathrm{f}$ and $3 \mathrm{~h}$ ). The decrease in size of the dispersed phase, the bond between the continuous and the dispersed phases, the irregular dispersed phase, and even the disappearance of the dispersed phase all suggested that loading G-POSS into the composite improved the compatibility between PCL and PPC by improving the interfaces between them [56]. This phenomenon could be attributed to the fact that G-POSS could enormously improve inter-/intra-molecular interactions (dipolar-dipolar and hydrogen-bonded interactions) between PPC and PCL, and as a result, the compatibility between the PPC and PCL was effectively enhanced. Therefore, one could conclude that G-POSS contributed to the miscibility of PCL and PPC by improving the interfaces of the PPC and PCL phases [3]. At the same time, sharper edges on the fracture-surfaces were observed for higher G-POSS contents. This phenomenon arose from the enhanced brittleness of the nanocomposites due to the presence of crystalline G-POSS nanoparticles [57]. This effect was approved later in the results of tensile tests.

Moreover, according to the EDX mapping images of the silica present in the G-POSS structure, the red dots that were the indication of the presence of nanoparticles were observed to be uniformly distributed throughout all samples containing up to $3 \mathrm{wt} \%$ 


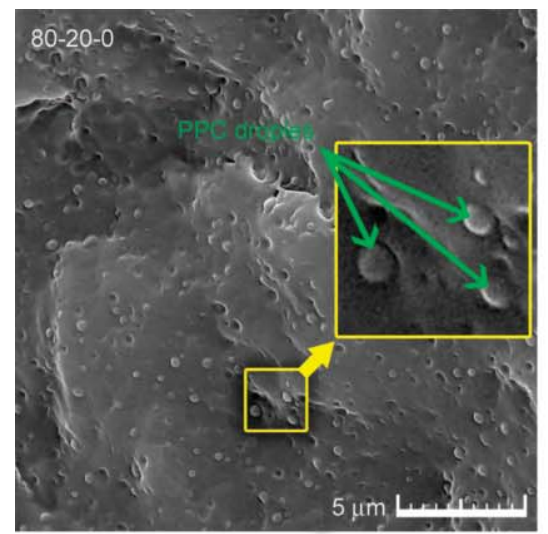

a)

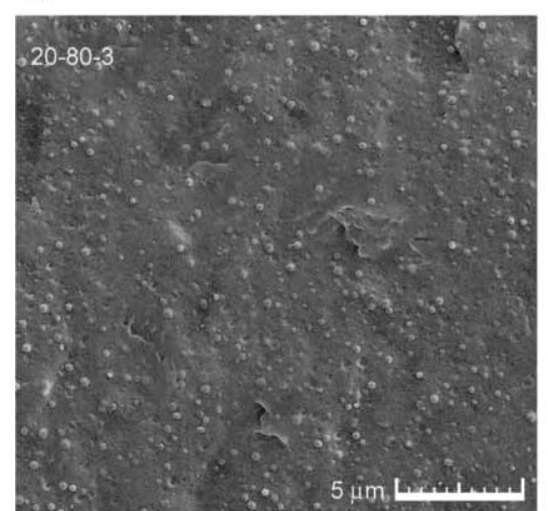

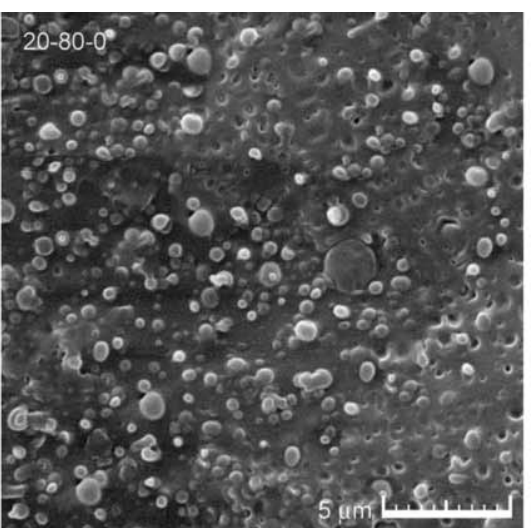

b)

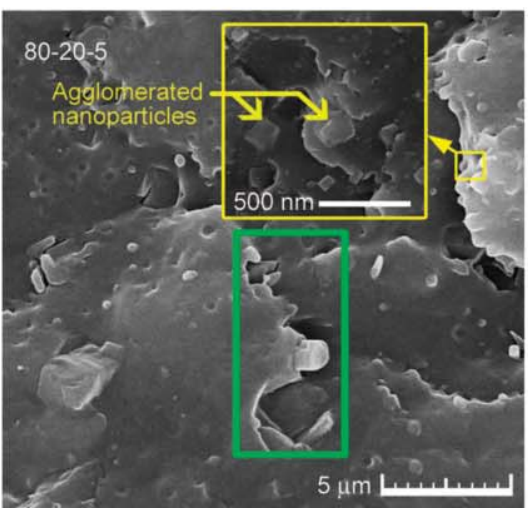

e)

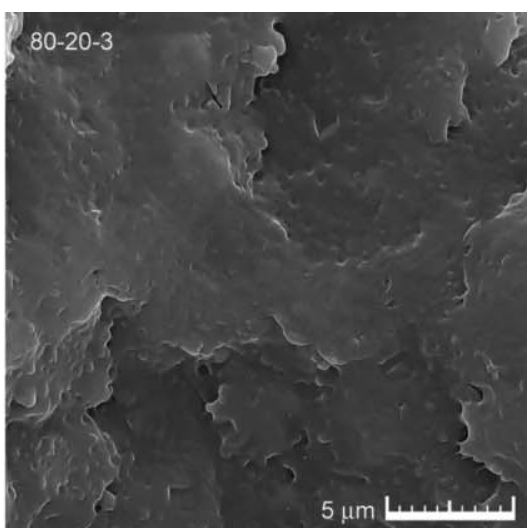

c)

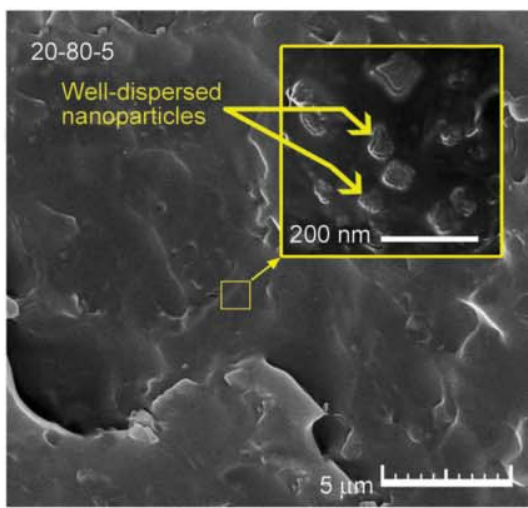

f)

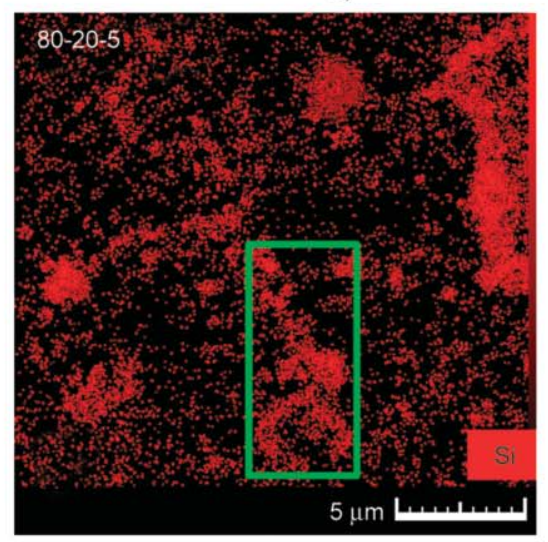

g)

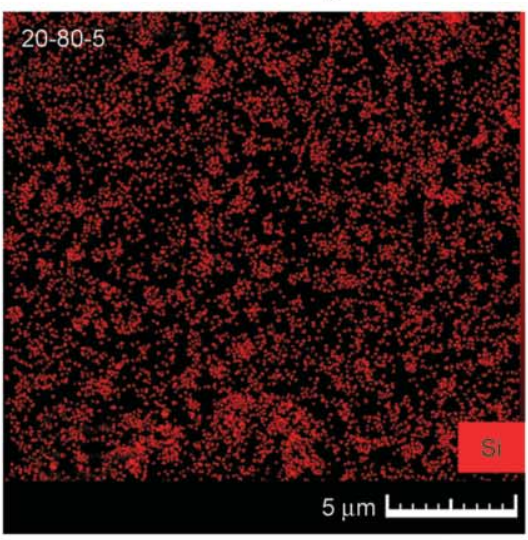

h)

Figure 3. The SEM images of the cryogenically fracture-surfaces of samples PL8-PC2-GP0 (a), PL2-PC8-GP0 (b), PL8PC2-GP3 (c), PL2-PC8-GP3 (d), PL8-PC2-GP5 (e), and PL2-PC8-GP5 (f) (Table 1); Energy dispersive X-ray (EDX) mapping of samples PL8-PC2-GP5 (g) and PL2-PC8-GP5 (h) (Table 1).

G-POSS (images of which are eliminated for brevity), and no agglomeration was observed. While by increasing the G-POSS content in the PCL-dominant compositions (PL10-PC0-GP5, PL8-PC2-GP5, and PL6-PC4-GP5 samples), the agglomerated nanoparticles with the dimensions of $200-500 \mathrm{~nm}$ in the designated areas of SEM images was observed, as exhibited in the SEM micrograph of Figure 3e, a fact which was also approved by the dots observed in the EDX mapping images, the nanoparticle distribution with the dimensions in the range of $20-150 \mathrm{~nm}$ in the PPC-dominant compositions was uniform up to
$5 \mathrm{wt} \%$ nanoparticle content, as observed in Figure $3 \mathrm{f}$ (PL4-PC6-GP5 and PL0-PC10-GP5 samples are not illustrated for brevity). Besides, by observing the position of red dots and the PPC droplets in Figure 4 where SEM and EDX micrographs are overlayed, it could be concluded that the concentration of nanoparticles where droplets were located was much higher, which approved their tendency of them to enter PPC and a higher chance of their distribution in this polymer. By considering this behavior of nanoparticles, it could be suggested that increasing the PPC content in nanocomposites led to increased space for the 


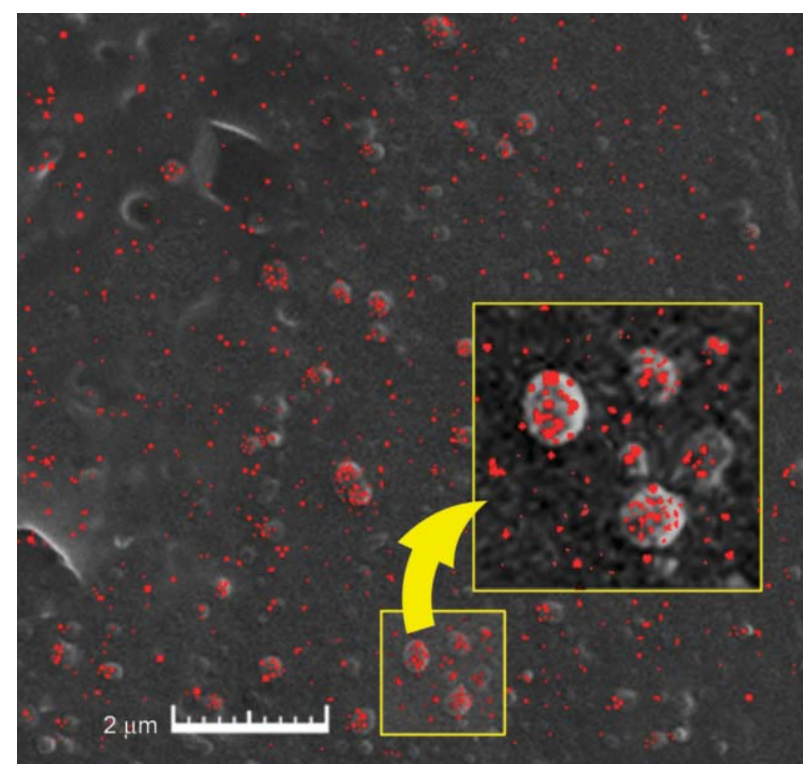

Figure 4. The overlayed SEM and EDX mapping of Si in sample PL2-PC8-GP3.

distribution of nanoparticles, and the capacity of samples with more PPC content to accept nanoparticles without their agglomeration increased [58]. This effect was observed because the functional group (active sites) of the PPC could effectively improve steric molecular interactions via G-POSS nanoparticles. On the other hand, functional groups of the G-POSS and PPC had better miscibility compared to the GPOSS and PCL [59]. This phenomenon was later approved by tensile and shape memory analysis.

Since plotting all stress-strain curves resulted from the tensile analysis was confusing, some of them are shown in Figures 5 and 6 to appreciate the changes in trends of the stress-strain behaviors with different PCL/PPC/G-POSS weight ratios. The entire data are summarized in Table 2 and plotted in Figure 7. Also, for better understanding the behaviors of the specimens for each property, the blends without nanoparticles were first investigated, followed by evaluating the effects of nanoparticles on all samples.

The stress-strain curve of the pure PCL exhibits a distinct yield strength value at a strain of $10.5 \%$, after which there is an extended flat region to the strain of $172 \%$, then an increase in the stress accompanied with fluctuations until complete failure, which is in line with previous studies and typical behavior for semicrystalline polymers [60]. However, as the PPC content was increased, the yield strength also increased, and it occurred at a lower strain, with the curve transforming from a distinct point into a smoother form and extended flat region after yielding altered to continuous growth until fracture. Also,

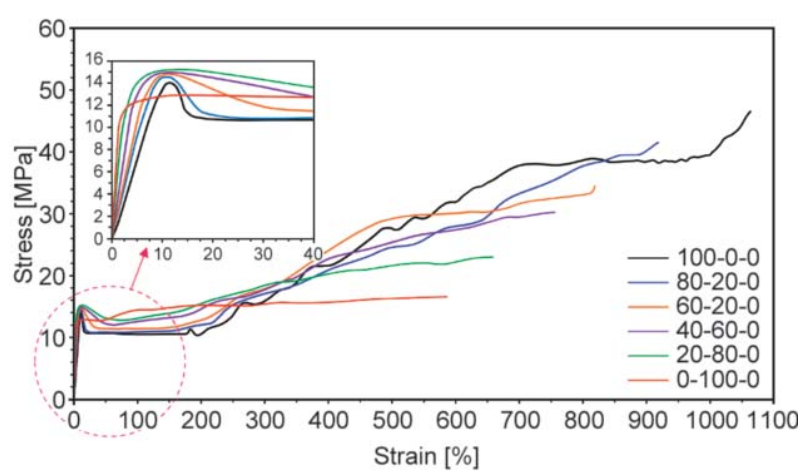

Figure 5. The stress-strain curves of the blends without nanoparticles.

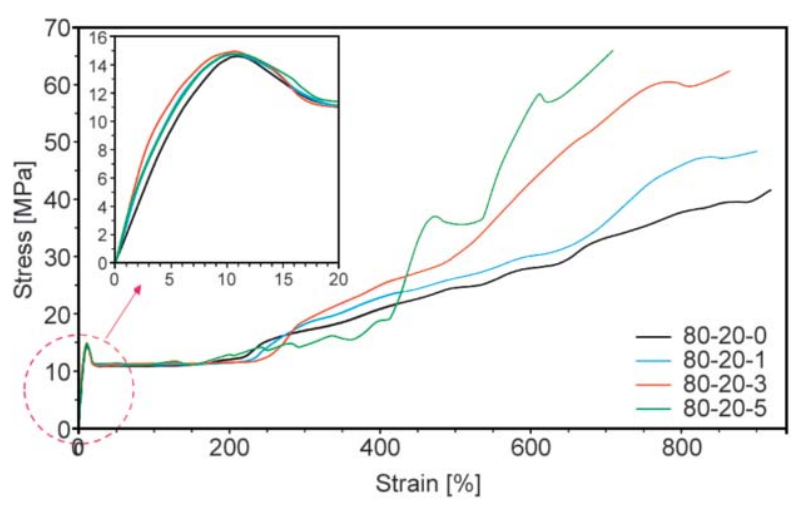

Figure 6. The uniaxial tensile stress-strain curves of specimens PL8-PC2-GP0, PL8-PC2-GP1, PL8-PC2GP3, and PL8-PC2-GP5.

for pure PPC, the yield strength was not evident, while stress increased, and after the flat region, fluctuations vanished, and the curve followed a relatively increasing trend. There was an increasing trend for the yield stress for the blends from pure PCL to the PL2PC8-GP0 sample. However, in contrast to the general trend, pure PPC started to yield in lower stress, which implies the reinforcing influence of PCL on PPC. Covalent bonding between PCL and PPC introduces branching into the linear PPC chain, which restricts polymer chain motions and sliding during periods of the applied load. Accordingly, strength and rigidity are enhanced [15]. Furthermore, the behaviors of the specimens until failure showed that the blends with dominant PCL contents experienced enhanced stress before failure, while those with dominant PPC contents mostly experienced no change in the stress before failure [61].

The elastic modulus was obtained by calculating the slopes of the curves in the linear region (i.e., typically initial $2 \%$ strain). The elastic modulus values of the blends without nanoparticles exhibited an increasing trend from $291 \mathrm{MPa}$ for PCL to $724 \mathrm{MPa}$ for PPC (Figure 7). The tensile strengths followed a 
reducing trend from $47 \mathrm{MPa}$ for pure PCL to 16.6 MPa for pure PPC. The elongation at break of the blends without nanoparticles decreased from $1060 \%$ for pure PCL to $586 \%$ for pure PPC, which

Table 2. The tensile tests result.

\begin{tabular}{|l|c|c|c|}
\hline Sample code & $\begin{array}{c}\text { Elastic } \\
\text { modulus } \\
\text { [MPa] }\end{array}$ & $\begin{array}{c}\text { Tensile } \\
\text { strength } \\
\text { [MPa] }\end{array}$ & $\begin{array}{c}\text { Elongation at } \\
\text { break } \\
\text { [\%] }\end{array}$ \\
\hline PL10-PC0-GP0 & 291 & 47.0 & 1060 \\
\hline PL10-PC0-GP1 & 304 & 53.6 & 1042 \\
\hline PL10-PC0-GP3 & 358 & 66.2 & 1021 \\
\hline PL10-PC0-GP5 & 293 & 63.0 & 807 \\
\hline PL8-PC2-GP0 & 326 & 41.7 & 927 \\
\hline PL8-PC2-GP1 & 346 & 48.4 & 899 \\
\hline PL8-PC2-GP3 & 404 & 62.4 & 864 \\
\hline PL8-PC2-GP5 & 347 & 65.1 & 709 \\
\hline PL6-PC4-GP0 & 451 & 33.5 & 819 \\
\hline PL6-PC4-GP1 & 490 & 39.8 & 759 \\
\hline PL6-PC4-GP3 & 561 & 54.9 & 713 \\
\hline PL6-PC4-GP5 & 528 & 67.6 & 621 \\
\hline PL4-PC6-GP0 & 518 & 30.1 & 756 \\
\hline PL4-PC6-GP1 & 580 & 37.6 & 667 \\
\hline PL4-PC6-GP3 & 650 & 56.2 & 602 \\
\hline PL4-PC6-GP5 & 637 & 81.6 & 559 \\
\hline PL2-PC8-GP0 & 575 & 22.9 & 659 \\
\hline PL2-PC8-GP1 & 669 & 29.7 & 534 \\
\hline PL2-PC8-GP3 & 736 & 48.2 & 472 \\
\hline PL2-PC8-GP5 & 772 & 85.2 & 450 \\
\hline PL0-PC10-GP0 & 724 & 16.6 & 586 \\
\hline PL0-PC10-GP1 & 898 & 21.6 & 429 \\
\hline PL0-PC10-GP3 & 1077 & 36.8 & 357 \\
\hline PL0-PC10-GP5 & 1174 & 72.1 & 347 \\
\hline
\end{tabular}

agrees with previous reports [52]. In order to depict the effect of nanocomposites in the mechanical behavior in the tensile mode, the stress-strain curves of PL8-PC2-GP0, PL8-PC2-GP1, PL8-PC2-GP3, and PL8-PC2-GP5 samples were chosen.

As shown in Figure 6, the trends of changes in the stress-strain curves of the nanocomposites demonstrated that adding up to $3 \%$ content of G-POSS to the PCL-dominant blends elevated the yield stress, elongated the flat region, and reduced the fluctuations during stress rise until failure, indicating that G-POSS nanocrystals acted as reinforcing fillers. However, this effect had a decreasing trend between 3-5\% content due to the agglomeration of nanoparticles in higher concentrations. Whereas, at higher PPC contents, when the G-POSS content increased, it was observed that no significant change happened in the general form of the curve, and only the elastic modulus, elongation at break, and tensile strength changed.

Investigating the elastic modulus results of all the specimens indicated that from pure PCL to PCL40/ PPC60, incorporating a G-POSS nanoparticle content higher than $3 \%$ to the polymer matrix reduced the elastic modulus compared to $3 \%$ specimens. However, as the PPC content was increased, an increasing trend was observed up to $5 \%$ content of nanoparticles (Figure 7). Figure 7 shows that by adding nanoparticles, the tensile strength of pure PCL increased up to the nanoparticle content of 3\%. The introduction of nanoparticles higher than 3\% content reduced the tensile strength, which was due

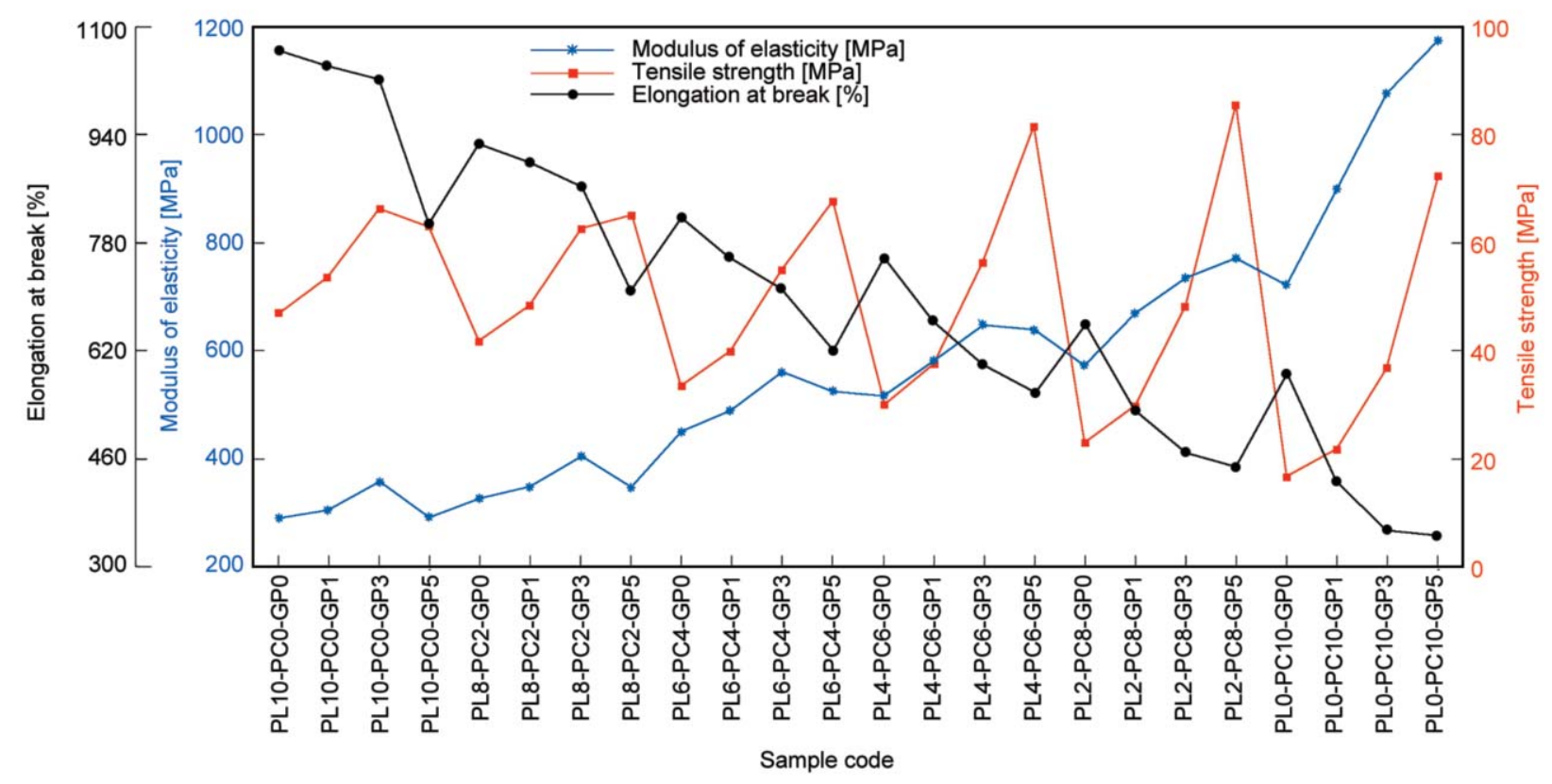

Figure 7. The elastic modulus, tensile strength and elongation at break of all specimens obtained by the uniaxial tensile tests. 
to the agglomeration of nanoparticles. However, the tensile strength of the other specimens increased, up to $5 \%$ nanoparticle content. As the PPC content increased, the effect of G-POSS incorporation on the tensile strength was enhanced, and the tensile strength of the specimens that were incorporated with nanoparticles followed a reducing trend. These two opposite behaviors led to the maximum tensile strength occurring in specimen PL2-PC8-GP5. Figure 7 shows that elongation at break followed a decreasing trend from $1060 \%$ for PL10-PC0-GP0 to $347 \%$ for specimen PL0-PC1-GP5. It was observed that adding up to $3 \%$ nanoparticle content to PCL slightly decreased the elongation at break, which was in line with previous reports [60]. However, when the nanoparticle content exceeded 3\%, a more significant reduction was induced in the elongation at break.

Like the previous sections, for the DMA test, the specimens without nanoparticles were investigated first. Figures 8 and 9 depict DMA plots of storage modulus $E^{\prime}$ and $\tan \delta$ versus temperature, respectively, which had useful data for shape memory properties and mechanical behavior investigations versus the variations in the temperature. As can be seen in Figure 8 , the $E^{\prime}$ curve of pure PCL exhibited two drops at -60 and $60^{\circ} \mathrm{C}$, which were the glass transition temperature and melting temperature, respectively. According to these data, since PCL was in the glassy state, it had a higher elastic modulus, and passing through this temperature range and transforming into the rubbery state caused a drop in the storage modulus. Subsequently, another drop in the plot, where the PCL turned from the rubbery to the melt state, was observed at about $60^{\circ} \mathrm{C}$.

However, when PPC was added, the drop in the modulus at -60 and $60^{\circ} \mathrm{C}$ was less intense, with a

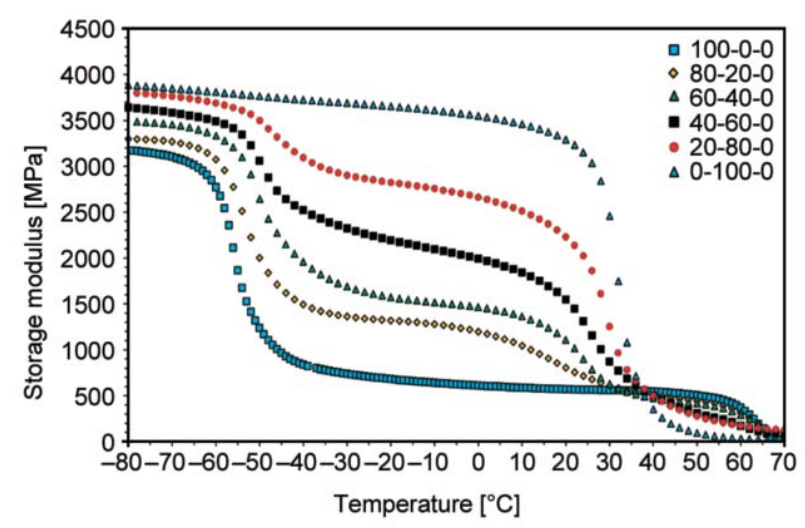

Figure 8. The storage modulus $E^{\prime}$ of the non-nanoparticle specimens. drop appearing at nearly $35^{\circ} \mathrm{C}$, representing the glass transition temperature of PPC. The drop at $35^{\circ} \mathrm{C}$ slightly shifted to the right as the PPC content increased, suggesting the low miscibility of PLC and PPC. The curve of pure PPC showed only one drop at approximately $35^{\circ} \mathrm{C}$. The storage modulus exhibits the capability of the material to store input energy, or in other words, maintaining the deformation resulted from bearing loads after unloading. Hence, the shape fixity ratio of SMP is directly related to this quantity, and, as later observed in shape memory tests, samples that evinced high storage modulus in low temperatures in the results of DMA tests had high shape fixity ratios.

Here, as observed in plots of Figure 8, since the elastic modulus of PPC was higher than that of PCL in the glassy state, the increase in the PPC content for the blends shifted the $E^{\prime}$ curve to the higher regions. Later, in the results of shape memory testes, it was revealed that the shape fixity rate was higher for samples with higher PPC contents. Besides, in these curved, it was observed that the $E^{\prime}$ curve of PPC underwent a more intense drop by passing through the glass transition region and approaches zero, compared to that of PCL.

As can be seen from Figure 9, the $\tan \delta$ curves of pure PCL and PPC exhibited an intense peak at approximately -60 and $35^{\circ} \mathrm{C}$, respectively. These temperatures are the glass transition temperatures of PCL and PPC, respectively. Also, intense peaks were observed in the curves of the PCL blends at approximately $60^{\circ} \mathrm{C}$, representing the melting temperature of PCL. On the other hand, for all samples, a reduction in the content of a polymer reduced the peak at its glass transition temperatures and enhanced the peak in the glass transition temperature of the other polymer whose content was increased. Whereas by

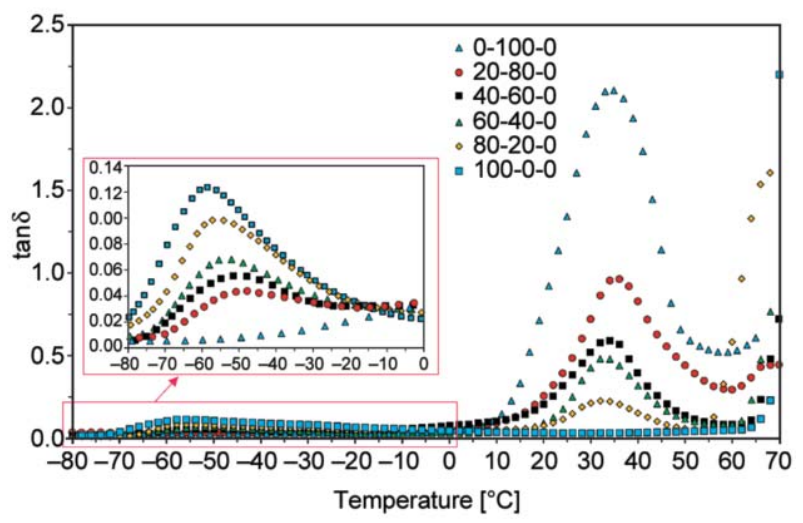

Figure 9. The $\tan \delta$ of the non-nanoparticle specimens for a temperature range of -80 to $70^{\circ} \mathrm{C}$. 
varying the weight ratios, the peaks shifted slightly towards each other, and the low miscibility of the polymers was concluded. However, this property could also be observed in the SEM images in which droplet-matrix with distinct boundaries could be observed.

Since demonstrating $E^{\prime}$ and $\tan \delta$ curves of all the nanocomposites in the same diagram could be confusing, to study the effect of incorporating G-POSS in blends, only those of specimens PL2-PC8-GP0, PL2-PC8-GP1, PL2-PC8-GP3, and PL2-PC8-GP5 are shown in Figures 10 and 11, as observed in Figure 10, increasing the G-POSS content led to an upward shift in $E^{\prime}$ curves, an effect that was more distinct in the $\left(-60^{\circ} \mathrm{C}\right)-\left(35^{\circ} \mathrm{C}\right)$ region. The reason for this behavior could be the fact that G-POSS played the role of the reinforcing agent of the PCL-PPC cross-links, which caused the energy storage.

For all blends, it was observed that the incorporation of more nanoparticles reduced the peaks at -60 and $35^{\circ} \mathrm{C}$ that were representing the glass transition temperature of PCL and PPC and slightly shifted them upwards. When the G-POSS content was increased,

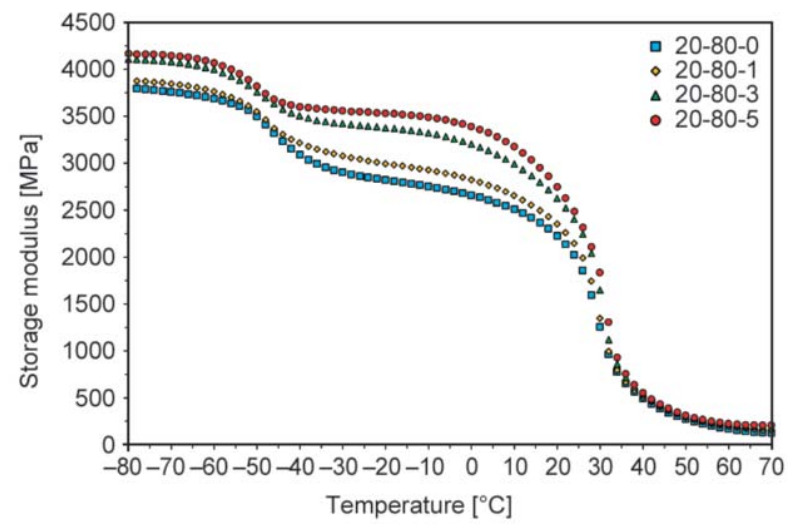

Figure 10. The storage modulus $E^{\prime}$ of specimens PL2-PC8GP0, PL2-PC8-GP1, PL2-PC8-GP3, and PL2PC8-GP5.

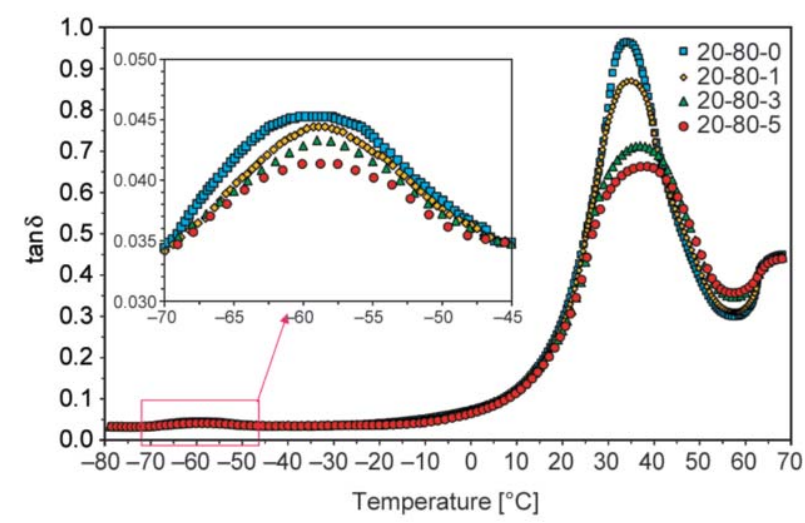

Figure 11. The $\tan \delta$ of specimens PL2-PC8-GP0, PL2-PC8GP1, PL2-PC8-GP3, and PL2-PC8-GP5. the cross-linking structure was more conjunct, and the restrictions in chain motions increased. To obtain the chain motion, samples that were cross-linked required more free space as well as more energy. Therefore, obtaining the energy for the chain motion demands a higher temperature. However, only when there was a higher temperature would the inside of the SMP nanocomposite have larger free space as well as more energy to realize the motion of the molecular chain segments, thus causing the increase of $T_{\mathrm{g}}$ [62]. These effects were more prominent for the peak at $35^{\circ} \mathrm{C}$ compared to the peak at $-60^{\circ} \mathrm{C}$ due to the high tendency of nanoparticles to enter the PPC phase, a fact which was approved by EDX mapping. As regards the compatibilizing effect of nanoparticle between the polymers, the presence of nanoparticles caused the peaks to shift towards each other slightly. Hence, increased nanoparticle content caused a rightward and a left-ward shift for the peak at $35^{\circ} \mathrm{C}$, the result of which was a slight shift towards the right. Therefore, for the peak at $-60^{\circ} \mathrm{C}$, since nanoparticle only partially entered the PCL phase, its effect on the polymer was negligible, and hence, the compatibilizing effect resulted from the incorporation of nanoparticles between PCL and PPC caused a slight rightward shift for the peak.

According to results obtained from DMA tests, the $T_{\mathrm{g}}$ of samples was in the $35^{\circ} \mathrm{C}$ region (glass transition temperature of PCC). The dumbbell-shaped specimens were subjected to shape memory cycles with $T_{1}=20^{\circ} \mathrm{C}$, and $T_{\mathrm{h}}=50^{\circ} \mathrm{C}$, under the typical conditions of shape memory cycles during the four steps explained mentioned above. The recovery and fixity ratios were calculated using Equations (1) and (2). Table 3 shows the results for all the specimens, and the results are also demonstrated in Figure 12. It was seen that the recovery ratio of specimens without nanoparticles increased from $44 \%$ for pure PCL to $90 \%$ for specimen PL2-PC8-GP0 and decreased to $69 \%$ for pure PCC. The maximum recovery ratio of 90\% in PL2-PC8-GP0 was 104 and 30\% more than PCL and PPC, respectively. This increase could be associated with the fact that the recovery ratio would be maximized at a specific ratio of $\mathrm{PC}$ to $\mathrm{SC}$ and the right amount of PCL crystalline parts due to the formation of the physical cross-links and optimizing the recoverability of the blend [50]. The low recovery rate for pure PPC is associated with the fact that it has no cross-links in the structure which are responsible for restoring the primary shape. Accordingly, the addition 
Table 3. The recovery ratio, fixity ratio and shape memory index results of the blends and nanocomposites.

\begin{tabular}{|c|c|c|c|}
\hline Sample code & $\begin{array}{c}\text { Recovery } \\
\text { ratio, } R_{\mathrm{r}} \\
{[\%]}\end{array}$ & $\begin{array}{c}\text { Fixity } \\
\text { ratio, } R_{\mathrm{f}} \\
{[\%]}\end{array}$ & $\begin{array}{l}\text { Shape memory } \\
\text { index, } \\
\frac{R_{\mathrm{r}} \cdot R_{\mathrm{f}}}{100} \\
{[\%]}\end{array}$ \\
\hline PL10-PC0-GP0 & 44 & 66 & 29.0 \\
\hline PL10-PC0-GP1 & 48 & 68 & 32.6 \\
\hline PL10-PC0-GP3 & 57 & 69 & 39.3 \\
\hline PL10-PC0-GP5 & 40 & 67 & 26.8 \\
\hline PL8-PC2-GP0 & 50 & 82 & 41.0 \\
\hline PL8-PC2-GP1 & 53 & 84 & 44.5 \\
\hline PL8-PC2-GP3 & 54 & 84 & 45.4 \\
\hline PL8-PC2-GP5 & 44 & 81 & 35.4 \\
\hline PL6-PC4-GP0 & 67 & 87 & 58.3 \\
\hline PL6-PC4-GP1 & 74 & 87 & 64.4 \\
\hline PL6-PC4-GP3 & 79 & 89 & 70.3 \\
\hline PL6-PC4-GP5 & 72 & 88 & 63.4 \\
\hline PL4-PC6-GP0 & 80 & 92 & 73.6 \\
\hline PL4-PC6-GP1 & 81 & 93 & 75.3 \\
\hline PL4-PC6-GP3 & 85 & 94 & 79.9 \\
\hline PL4-PC6-GP5 & 89 & 96 & 85.4 \\
\hline PL2-PC8-GP0 & 90 & 97 & 87.3 \\
\hline PL2-PC8-GP1 & 92 & 97 & 89.2 \\
\hline PL2-PC8-GP3 & 91 & 98 & 89.2 \\
\hline PL2-PC8-GP5 & 95 & 98 & 93.1 \\
\hline PL0-PC10-GP0 & 69 & 98 & 67.6 \\
\hline PL0-PC10-GP1 & 72 & 98 & 70.6 \\
\hline PL0-PC10-GP3 & 77 & 99 & 76.2 \\
\hline PL0-PC10-GP5 & 79 & 99 & 78.2 \\
\hline
\end{tabular}

of PCL may affect the recoverability of the blend negatively. On the other hand, the molecular chains of crystalline domains of PCL deform irreversibly, which lead to inferior recovery [25, 63-65]. For samples sans nanoparticles, the shape fixity ratios increased from a minimum of $66 \%$ for pure PCL to a maximum of $98 \%$ for pure PPC with a relatively uniform trend. Since the temporary shape fixity rate only depended on the PPC content of blends, which were capable of maintaining the induced shape change in the glassy state, the shape fixity rate had an increasing trend when the content of this polymer was increased in the blends [27].

It is generally reported that adding POSS to nanocomposites enhances the shape recovery stress levels for shape memory polymers [51]. From Pure-PCLbased nanocomposites to the ones containing $60 \%$ PCL, the maximum recovery ratio and fixity ratio occurred in the specimens with a $3 \%$ nanoparticle content and then continued to increase by adding up to $5 \%$ nanoparticles with lower contents of PCL. As can be seen from Table 3, the minimum and maximum shape recovery ratios were obtained to be 40 and $95 \%$ for specimens PL10-PC0-GP5 and PL2-PC8-GP5, respectively. The analysis conducted here exhibited that adding POSS nanoparticles to the blends enhanced the shape recovery property of the sample considerably, even when cross-links were not present in the structure (pure PPC). The reduced shape

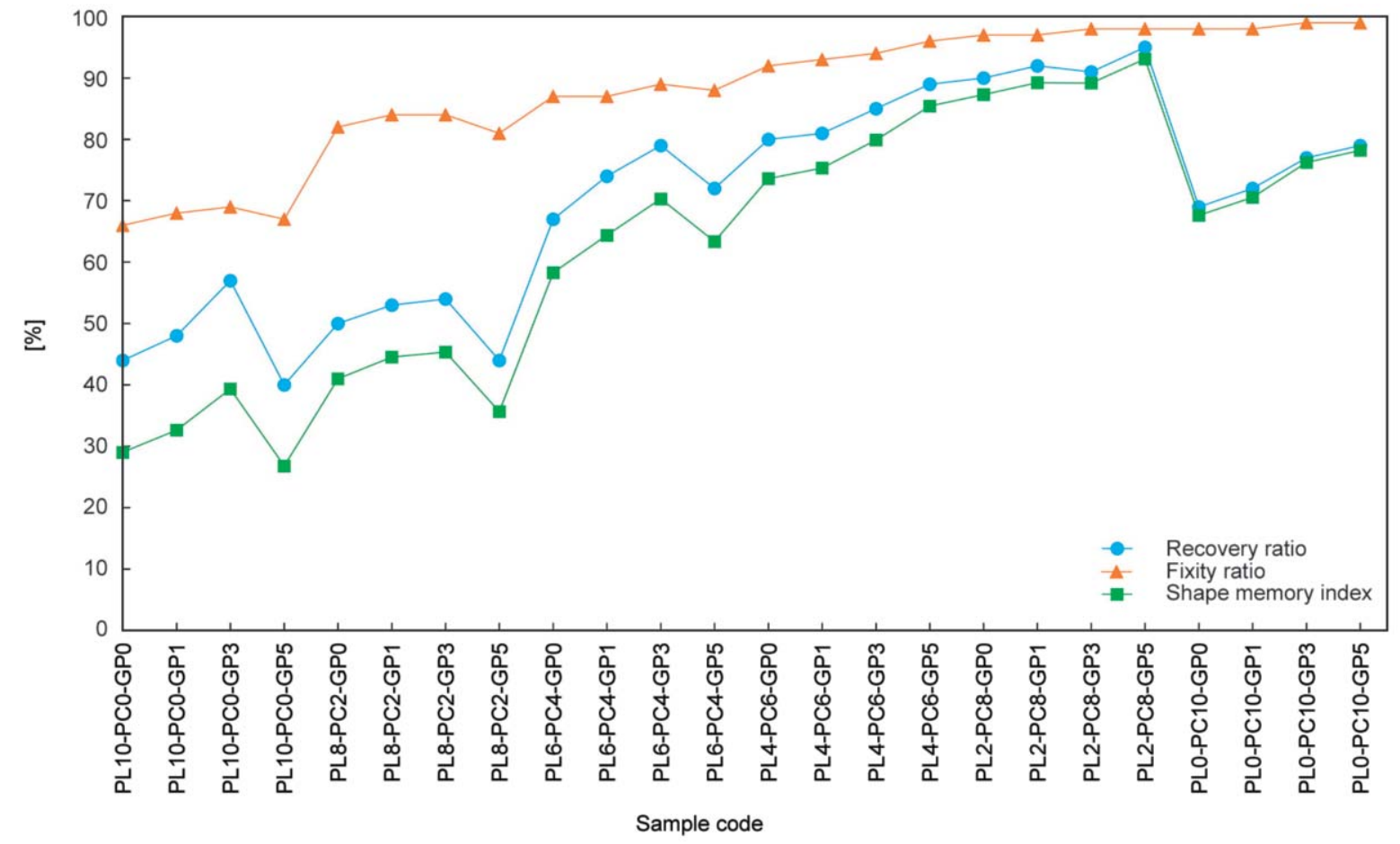

Figure 12. The recovery ratio, fixity ratio, and shape memory index of all the specimens. 
recovery ratios of the specimens PL10-PC0-GP5, PL8-PC2-GP5, and PL6-PC4-GP5 could be attributed to the aggregation of nanoparticles and reduction of recovery force, which was supported by SEM photographs and EDX mapping. Agglomerated G-POSS particles behaved like rigid obstacles that prevented the cross-linking reaction and restricted the movement of PPC molecular chains, thereby decreased the recovery ratio [66].

The trend of changes in the shape fixity ratio was less complicated since these changes did not depend on cross-links [49]. As exhibited in Figure 12, except for samples where agglomeration of nanoparticles occurred, the shape fixity rate increased dramatically with increasing the PPC content and increasing the nanoparticle content to some extent. In the stretched state, after cooling the sample down to room temperature, SC PPC was in the glassy state that supported enough hindrance to prevent the chains of the stretched soft phases to relax [67]. The presence of nanoparticles, which had a crystalline nature, aided the formation and maintaining the temporary shape in the glassy state of PPC and enhanced the fixity rate to some extent [68].

In order to introduce the composition with optimum shape memory properties, both recovery and fixity ratios should be considered simultaneously. Therefore, further denotation of shape memory index, $R_{\mathrm{r}} \cdot R_{\mathrm{f}}$, to combine both ratios by the multiplication of recovery ratio and fixity ratio was employed. [69]. Even though there is no much physical interpretation for this coupling denotation, it is rather informative to have this distinct value as an index. When the value of the shape memory index was closed to $100 \%$, the materials presented the highest shape memory effect. The results of the shape memory index are also demonstrated in Figure 12.

As demonstrated in the shape memory index diagram, the sample with the optimum shape fixity and shape recovery is the PL2-PC8-GP5 sample, which had the shape fixity rate of $98 \%$ and shape recovery rate of $95 \%$. Studying the shape memory index results for pure PPC nanocomposites revealed that despite the high shape fixity rate for these samples since they did not show high recovery rates, their shape memory indexes were lower compared to nanocomposites based on the PCL20/PPC80 blend. Therefore, it seemed that this index was a desirable criterion for comparing the shape memory property of materials that comprised both shape fixity and recovery rates simultaneously. Since the recovery time reported by Zheng et al. [50] for PCL20/PPC80 blend was $25 \mathrm{~s}$ at the same temperature, which was a considerable number, the recovery times of PL20PC80-GP0 and PL20-PC80-GP5 samples were measured to investigate the effect of introducing nanoparticles in them, and the considerable decrease in the recovery time from 27 to $17 \mathrm{~s}$ in the presence of $5 \mathrm{wt} \%$ nanoparticle content was recorded. The drop in the induction time in the presence of nanoparticles could be caused by two factors: 1) the increase in the heat transfer coefficient since the G-POSS nanoparticles had a high heat transfer coefficient [38], and 2 ) the stress transfer between phases was improved due to the improved interface between them [19, 20, 51, 70-72]. Chatterjee and Naskar [51] and Gu et al. [68] have previously reported the increase in the recovery rate in the presence of these nanoparticles.

As reported in the studies of $[25,34,64]$, PCL has a semicrystalline structure in the $\left(-60^{\circ} \mathrm{C}\right)-\left(60^{\circ} \mathrm{C}\right)$ temperature range. As expected, the crystalline parts of semicrystalline PCL with lattice structures functioning as permanent components were connected by PPC and amorphous parts of PCL, which were acting as cross-links or switching components [27, 73]. In such a structure, G-POSS improved compatibility and cross-links and led to a higher recoverability. It could be concluded that the nanoparticles entering the PCC phases of the blends enhanced the recoverability of the switching components to the original shape. Moreover, in PCL100/PPC0, PCL80/PPC20, and PCL60/PPC40 compositions, the higher content of G-POSS (more than 3\%) led to less favorable distributions, which considerably decreased the mechanical and shape memory properties of the nanocomposites [74]. The maximum recovery ratio of 95\% took place for specimen PL2-PC8-GP5, which showed a $116 \%$ increase compared to pure PCL and a $38 \%$ increase compared to pure PPC. Also, considering the SEM results on improved PCL/PPC interfaces due to G-POSS, it could be said that the presence of G-POSS improved cross-linking. This mechanism is illustrated in Figure 13, where the trends of variations in the nanocomposites' structure during the fixing and recovery steps are depicted. In Figure 13, the PCL/PPC/G-POSS nanocomposites were composed of four components: (1) permanent components, which are the crystalline parts of PCL, (2) switching components, which consist of nanoparticles containing PPC chains, (3) amorphous parts of 


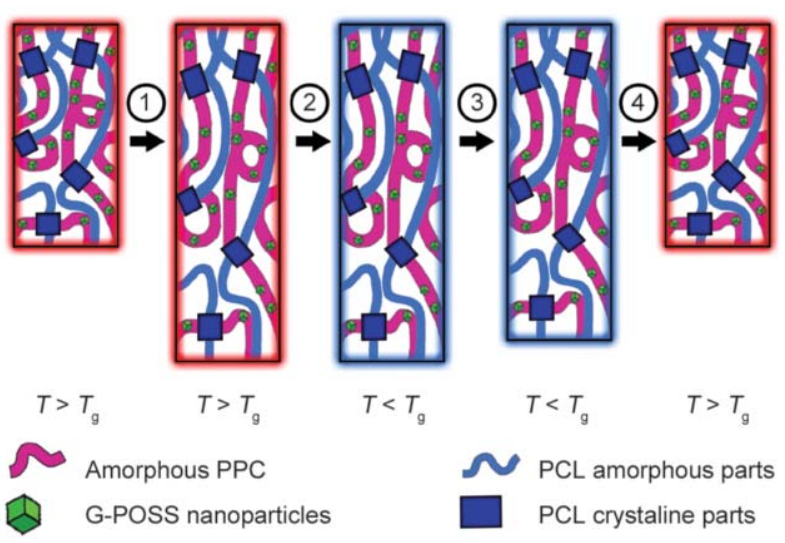

Figure 13. Schematic illustration of the PCL/PPC/G-POSS mechanism during the shape memory cycle (numbers represent the shape memory cycle typical courses in Figure 2).

PCL, and (4) G-POSS nanoparticles. Similar illustrations are suggested in the studies by $[30,33,41$, $44,50,71]$, which are drawn for the semicrystalline PCL and amorphous polymer blends. Hence, the reduced recovery ratio of pure PPC arose from the absence of permanent components. Furthermore, the $\tan \delta$ curves obtained from the DMA tests confirmed the improving effects of G-POSS in the blends on recovery at $35^{\circ} \mathrm{C}[10]$. Generally, the fixity ratio was improved by an increase in either PPC or G-POSS contents, except where agglomeration occurred. Nevertheless, introducing nanoparticles into the blends did not considerably increase the shape fixity ratio of them.

As observed in the results of shape memory tests, each of the two polymers was not of desirable shape memory properties alone, which was due to the lack of cross-links in their structure that are required for shape memory property. It was observed that PPC had an eligible shape fixity capability alone, but since no fixed points were present in its structure, it was not capable of recovering the initial shape. Pure PCL did not have transition temperature in the temperature range of the shape memory cycle (body temperature) and underwent shape recession after unloading. Hence, it was observed that by mixing a favorable composition of the two polymers, a blend with a high shape memory property resulted in the PCL20/PPC80 composition, and introducing nanoparticles to this blend led to better physical crosslinks and, therefore, higher shape fixity and recovery ratios and faster recovery due to improvement in polymers interface. Accordingly, when functional groups of G-POSS had a preference to form chemical bonding between the polymer chain and G-POSS nanoparticles, the said interface is formed [75]. The optimum content of nanoparticles for PCL100/ PPC80, PCL80/PPC20, and PCL60/PPC40 blending ratios was $3 \%$, and for blends with higher PPC content, the nanoparticle content of up to $5 \%$ improved the mechanical and shape properties.

\section{Conclusions}

In this study, PCL/PPC polymeric blends were prepared in the presence of G-POSS nanoparticles, and morphological, mechanical, and shape memory properties were studied. For blends sans nanoparticles, increased PPC content led to increased elastic modulus and tensile strength and decreased elongation at break. The results indicate that the G-POSS nanoparticles improved the interface of the two polymers and, consequently, their compatibility, mechanical, and shape memory properties. In this work, the shape memory index, which comprised both shape fixity and shape recovery rates simultaneously, was calculated, and the sample with the most favorable shape memory properties, was suggested. The sample with PCL20/PPC80 composition and $5 \mathrm{wt} \%$ G-POSS content was chosen as the optimum sample. The said sample showed remarkable short recovery time in the physiological temperature of the body, which was lower compared to other nanocomposites reported in the literature. A significant improvement in the shape memory properties of the suggested sample was observed compared to each polymer.

Due to the more favorable distribution of nanoparticles in PPC domains compared to PCL ones, improvement in mechanical and shape memory properties continued to higher nanoparticle concentrations in PPC-rich blends. The obtained nanocomposites possessed exclusive shape memory and mechanical properties that made them potential candidates for medical applications, and they were suggested for further studies.

\section{References}

[1] Gandhi M. V., Thompson B.: Smart materials and structures. Springer, Berlin (1992).

[2] Muzaffar A., Deshmukh K., Ahamed M. B., Pasha S. K.: Shape memory polymer composites in biomedical field. in 'Polymer nanocomposites in biomedical engineering' (eds.: Sadasivuni K. K.) Springer, Berlin, Vol 1, 299329 (2019).

https://doi.org/10.1007/978-3-030-04741-2_10 
[3] Arun D., Chakravarthy P., Kumar A., Santhosh B.: Shape memory materials. CRC Press, Boca (2018).

[4] Serrano M. C., Ameer G. A.: Recent insights into the biomedical applications of shape-memory polymers. Macromolecular Bioscience, 12, 1156-1171 (2012). https://doi.org/10.1002/mabi.201200097

[5] Dell'Erba R., Groeninckx G., Maglio G., Malinconico M., Migliozzi A.: Immiscible polymer blends of semicrystalline biocompatible components: Thermal properties and phase morphology analysis of PLLA/PCL blends. Polymer, 42, 7831-7840 (2001). https://doi.org/10.1016/S0032-3861(01)00269-5

[6] Albuerne J., Márquez L., Müller A., Raquez J., Degée P., Dubois P., Castelletto V., Hamley I.: Nucleation and crystallization in double crystalline poly( $p$-dioxanone)$b$-poly( $\varepsilon$-caprolactone) diblock copolymers. Macromolecules, 36, 1633-1644 (2003).

https://doi.org/10.1021/ma025766t

[7] Semba T., Kitagawa K., Ishiaku U. S., Hamada H.: The effect of crosslinking on the mechanical properties of polylactic acid/polycaprolactone blends. Journal of Applied Polymer Science, 101, 1816-1825 (2006).

https://doi.org/10.1002/app.23589

[8] Yeganeh H., Jamshidi H., Jamshidi S.: Synthesis and properties of novel biodegradable poly( $\varepsilon$-caprolactone)/ poly(ethylene glycol)-based polyurethane elastomers. Polymer International, 56, 41-49 (2007).

https://doi.org/10.1002/pi.2107

[9] Ratna D., Karger-Kocsis J.: Recent advances in shape memory polymers and composites: A review. Journal of Materials Science, 43, 254-269 (2008). https://doi.org/10.1007/s10853-007-2176-7

[10] Ajili S. H., Ebrahimi N. G., Soleimani M.: Polyurethane/polycaprolactane blend with shape memory effect as a proposed material for cardiovascular implants. Acta Biomaterialia, 5, 1519-1530 (2009).

https://doi.org/10.1016/j.actbio.2008.12.014

[11] Aghdam R. M., Najarian S., Shakhesi S., Khanlari S., Shaabani K., Sharifi S.: Investigating the effect of PGA on physical and mechanical properties of electrospun PCL/PGA blend nanofibers. Journal of Applied Polymer Science, 124, 123-131 (2012).

https://doi.org/10.1002/app.35071

[12] Chang L. C., Read T. A.: Plastic deformation and diffusionless phase changes in metals - The gold-cadmium beta phase. JOM, 3, 47-52 (1951). https://doi.org/10.1007/BF03398954

[13] El Feninat F., Laroche G., Fiset M., Mantovani D.: Shape memory materials for biomedical applications. Advanced Engineering Materials, 4, 91-104 (2002).

https://doi.org/10.1002/1527-2648(200203)4:3\%3C91::AIDADEM91\%3E3.0.CO;2-B

[14] Sokolowski W., Metcalfe A., Hayashi S., Yahia L., Raymond J.: Medical applications of shape memory polymers. Biomedical Materials, 2, S23-S27 (2007). https://doi.org/10.1088/1748-6041/2/1/S04
[15] Murphy C. J., Gole A. M., Stone J. W., Sisco P. N., Alkilany A. M., Goldsmith E. C., Baxter S. C.: Gold nanoparticles in biology: Beyond toxicity to cellular imaging. Accounts of Chemical Research, 41, 1721-1730 (2008). https://doi.org/10.1021/ar800035u

[16] Xiao Y., Zhou S., Wang L., Gong T.: Electro-active shape memory properties of poly( $\varepsilon$-caprolactone)/functionalized multiwalled carbon nanotube nanocomposite. ACS Applied Materials and Interfaces, 2, 35063514 (2010). https://doi.org/10.1021/am100692n

[17] Yadav S. K., Yoo H. J., Cho J. W.: Click coupled graphene for fabrication of high-performance polymer nanocomposites. Journal of Polymer Science Part B: Polymer Physics, 51, 39-47 (2013). https://doi.org/10.1002/polb.23155

[18] Lee Y., Kim D., Seo J., Han H., Khan S. B.: Preparation and characterization of poly(propylene carbonate)/exfoliated graphite nanocomposite films with improved thermal stability, mechanical properties and barrier properties. Polymer International, 62, 1386-1394 (2013). https://doi.org/10.1002/pi.4434

[19] Ebadi-Dehaghani H., Khonakdar H. A., Barikani M., Jafari S. H.: Experimental and theoretical analyses of mechanical properties of PP/PLA/clay nanocomposites. Composites Part B: Engineering, 69, 133-144 (2015). https://doi.org/10.1016/j.compositesb.2014.09.006

[20] Barmouz M., Behravesh A. H.: Shape memory behaviors in cylindrical shell PLA/TPU-cellulose nanofiber bio-nanocomposites: Analytical and experimental assessment. Composites, 101, 160-172 (2017). https://doi.org/10.1016/j.compositesa.2017.06.014

[21] Mahdavi R., Goodarzi V., Khonakdar H. A., Jafari S. H., Saeb M. R., Shojaei S.: Experimental analysis and prediction of viscoelastic creep properties of PP/EVA/LDH nanocomposites using master curves based on timetemperature superposition. Journal of Applied Polymer Science, 135, 46725/1-46725/12 (2018).

https://doi.org/10.1002/app.46725

[22] Mosleh Y., Ebrahimi N. G., Mahdavian A., Ashjari M.: TPU/PCL/nanomagnetite ternary shape memory composites: Studies on their thermal, dynamic-mechanical, rheological and electrical properties. Iranian Polymer Journal, 23, 137-145 (2014). https://doi.org/10.1007/s13726-013-0209-4

[23] Mi H-Y., Jing X., Peng J., Salick M. R., Peng X-F., Turng L-S.: Poly(E-caprolactone) (PCL)/cellulose nanocrystal (CNC) nanocomposites and foams. Cellulose, 21, 2727-2741 (2014). https://doi.org/10.1007/s10570-014-0327-y

[24] Yin G., Zhang L., Li Q.: Preparation and characterization of poss-crosslinked PCL based hybrid materials. Journal of Polymer Research, 23, 138/1-138/11 (2016). https://doi.org/10.1007/s10965-016-1028-z 
[25] Jing X., Mi H-Y., Huang H-X., Turng L-S.: Shape memory thermoplastic polyurethane (TPU)/poly( $\varepsilon$ caprolactone) (PCL) blends as self-knotting sutures. Journal of the Mechanical Behavior of Biomedical Materials, 64, 94-103 (2016).

https://doi.org/10.1016/j.jmbbm.2016.07.023

[26] Ur Rehman H., Chen Y., Hedenqvist M. S., Li H., Xue W., Guo Y., Guo Y., Duan H., Liu H.: Self-healing shape memory PUPCL copolymer with high cycle life. Advanced Functional Materials, 28, 1704109/1-1704109/13 (2018). https://doi.org/10.1002/adfm.201704109

[27] Liu W., Zhang R., Huang M., Dong X., Xu W., Ray N., Zhu J.: Design and structural study of a triple-shape memory PCL/PVC blend. Polymer, 104, 115-122 (2016). https://doi.org/10.1016/j.polymer.2016.09.079

[28] Koenig M. F., Huang S. J.: Biodegradable blends and composites of polycaprolactone and starch derivatives. Polymer, 36, 1877-1882 (1995). https://doi.org/10.1016/0032-3861(95)90934-T

[29] Mishra J. K., Chang Y-W., Kim D-K.: Green thermoplastic elastomer based on polycaprolactone/epoxidized natural rubber blend as a heat shrinkable material. Materials Letters, 61, 3551-3554 (2007).

https://doi.org/10.1016/j.matlet.2006.11.119

[30] Woodruff M. A., Hutmacher D. W.: The return of a forgotten polymer-polycaprolactone in the $21^{\text {st }}$ century. Progress in Polymer Science, 35, 1217-1256 (2010). https://doi.org/10.1016/j.progpolymsci.2010.04.002

[31] Schuh C., Schuh K., Lechmann M. C., Garnier L., Kraft A.: Shape-memory properties of segmented polymers containing aramid hard segments and polycaprolactone soft segments. Polymers, 2, 71-85 (2010). https://doi.org/10.3390/polym2020071

[32] Chen W-C., Lai S-M., Chang M., Liao Z-C.: Preparation and properties of natural rubber (NR)/polycaprolactone (PCL) bio-based shape memory polymer blends. Journal of Macromolecular Science Part B: Physics, 53, 645-661 (2014).

https://doi.org/10.1080/00222348.2013.860304

[33] Joo Y-S., Cha J-R., Gong M-S.: Biodegradable shapememory polymers using polycaprolactone and isosorbide based polyurethane blends. Materials Science and Engineering: C, 91, 426-435 (2018).

https://doi.org/10.1016/j.msec.2018.05.063

[34] Schäfer H., Kolberg A., Gockeln M., Kun R., Balzer B. N., Koschek K.: Influence of free PCL in PCL/PBA-A copolymers and blends on morphology, thermo-mechanical and shape memory properties. Polymer Testing, 77, 105888/1-105888/8 (2019). https://doi.org/10.1016/j.polymertesting.2019.05.004

[35] Lorwanishpaisarn N., Kasemsiri P., Jetsrisuparb K., Knijnenburg J. T. N., Hiziroglu S., Pongsa U., Chindaprasirt P., Uyama H.: Dual-responsive shape memory and self-healing ability of a novel copolymer from epoxy/cashew nut shell liquid and polycaprolactone. Polymer Testing, 81, 106159/1-106159/14 (2020). https://doi.org/10.1016/j.polymertesting.2019.106159
[36] Qin Y., Wang X.: Carbon dioxide-based copolymers: Environmental benefits of PPC, an industrially viable catalyst. Biotechnology Journal, 5, 1164-1180 (2010). https://doi.org/10.1002/biot.201000134

[37] Jeon H. G., Mather P. T., Haddad T. S.: Shape memory and nanostructure in poly(norbornyl-POSS) copolymers. Polymer International, 49, 453-457 (2000). https://doi.org/10.1002/(SICI)10970126(200005)49:5\%3C453::AID-PI332\%3E3.0.CO;2-H

[38] Joshi M., Butola B. S.: Polymeric nanocompositespolyhedral oligomeric silsesquioxanes (POSS) as hybrid nanofiller. Journal of Macromolecular Science Part C: Polymer Reviews, 44, 389-410 (2004).

https://doi.org/10.1081/MC-200033687

[39] Kannan R. Y., Salacinski H. J., De Groot J., Clatworthy I., Bozec L., Horton M., Butler P. E., Seifalian A. M.: The antithrombogenic potential of a polyhedral oligomeric silsesquioxane (POSS) nanocomposite. Biomacromolecules, 7, 215-223 (2006).

https://doi.org/10.1021/bm050590z

[40] Shen C., Han Y., Wang B., Tang J., Chen H., Lin Q.: Ocular biocompatibility evaluation of POSS nanomaterials for biomedical material applications. RSC Advances, 5, 53782-53788 (2015).

https://doi.org/10.1039/C5RA08668J

[41] Lee K. M., Knight P. T., Chung T., Mather P. T.: Polycaprolactone-POSS chemical/physical double networks. Macromolecules, 41, 4730-4738 (2008). https://doi.org/10.1021/ma800586b

[42] Mya K. Y., Gose H. B., Pretsch T., Bothe M., He C.: Star-shaped poss-polycaprolactone polyurethanes and their shape memory performance. Journal of Materials Chemistry, 21, 4827-4836 (2011). https://doi.org/10.1039/C0JM04459H

[43] Alvarado-Tenorio B., Romo-Uribe A., Mather P. T.: Microstructure and phase behavior of POSS/PCL shape memory nanocomposites. Macromolecules, 44, 56825692 (2011). https://doi.org/10.1021/ma2005662

[44] Bothe M., Mya K. Y., Lin E. M. J., Yeo C. C., Lu X., He C., Pretsch T.: Triple-shape properties of star-shaped POSS-polycaprolactone polyurethane networks. Soft Matter, 8, 965-972 (2012). https://doi.org/10.1039/C1SM06474F

[45] Alvarado-Tenorio B., Romo-Uribe A., Mather P. T.: Nanoscale order and crystallization in POSS-PCL shape memory molecular networks. Macromolecules, 48, 5770-5779 (2015). https://doi.org/10.1021/acs.macromol.5b01409

[46] Yang D., Gao D., Zeng C., Jiang J., Xie M.: POSS-enhanced shape-memory copolymer of polynorbornene derivate and polycyclooctene through ring-opening metathesis polymerization. Reactive and Functional Polymers, 71, 1096-1101 (2011). https://doi.org/10.1016/j.reactfunctpolym.2011.08.009 
[47] Meng Q., Hu J.: A review of shape memory polymer composites and blends. Composites Part A: Manufacturing, 40, 1661-1672 (2009).

https://doi.org/10.1016/j.compositesa.2009.08.011

[48] Kannan R. Y., Salacinski H. J., Butler P. E., Seifalian A. M.: Polyhedral oligomeric silsesquioxane nanocomposites: The next generation material for biomedical applications. Accounts of Chemical Research, 38, 879884 (2005).

https://doi.org/10.1021/ar050055b

[49] Yang Z-X., Chen Y., Liu X., Yin B., Yang M-B.: Fabrication of poly( $\varepsilon$-caprolactone) (PCL)/poly(propylene carbonate) (PPC)/ethylene- $\alpha$-octene block copolymer (OBC) triple shape memory blends with cycling performance by constructing a co-continuous phase morphology. Polymer International, 69, 702-711 (2020). https://doi.org/10.1002/pi.6005

[50] Zheng Y., Li Y., Hu X., Shen J., Guo S.: Biocompatible shape memory blend for self-expandable stents with potential biomedical applications. ACS Applied Materials Interfaces, 9, 13988-13998 (2017).

https://doi.org/10.1021/acsami.7b04808

[51] Chatterjee T., Naskar K.: Thermo-sensitive shape memory polymer nanocomposite based on polyhedral oligmeric silsesquioxane (POSS) filled polyolefins. Polymer-Plastics Technology and Materials, 58, 630-640 (2019).

https://doi.org/10.10180/03602559.2018.1493127

[52] Navarro-Baena I., Sessini V., Dominici F., Torre L., Kenny J. M., Peponi L.: Design of biodegradable blends based on PLA and PCL: From morphological, thermal and mechanical studies to shape memory behavior. Polymer Degradation and Stability, 132, 97-108 (2016). https://doi.org/10.1016/j.polymdegradstab.2016.03.037

[53] Molavi F. K., Ghasemi I., Messori M., Esfandeh M.: Design and characterization of novel potentially biodegradable triple-shape memory polymers based on immiscible poly(L-lactide)/poly( $\varepsilon$-caprolactone) blends. Journal of Polymers and the Environment, 27, 632-642 (2019).

https://doi.org/10.1007/s10924-019-01366-6

[54] Cunha S., Gaspar-Cunha A., Covas J.: Morphology development of immiscible polymer blends during melting in single-screw extruders: Effect of composition and compatibilization. in 'PPS 27-Proceedings of the Polymer Processing Society Annual Meeting. Marrakech, Morocco' Vol 27, 1-4 (2011).

[55] Pan D., Hufenus R., Qin Z., Chen L., Gooneie A.: Tuning gradient microstructures in immiscible polymer blends by viscosity ratio. Journal of Applied Polymer Science, 136, 48165/1-48165/9 (2019).

https://doi.org/10.1002/app.48165
[56] Qin S-X., Yu C-X., Chen X-Y., Zhou H-P., Zhao L-F.: Fully biodegradable poly(lactic acid)/poly(propylene carbonate) shape memory materials with low recovery temperature based on in situ compatibilization by dicumyl peroxide. Chinese Journal of Polymer Science, 36, 783-790 (2018).

https://doi.org/10.1007/s10118-018-2065-3

[57] Yari H., Mohseni M., Messori M.: Toughened acrylic/ melamine thermosetting clear coats using POSS molecules: Mechanical and morphological studies. Polymer, 63, 19-29 (2015).

https://doi.org/10.1016/j.polymer.2015.02.040

[58] Salehiyan R., Ray S. S.: Tuning the conductivity of nanocomposites through nanoparticle migration and interface crossing in immiscible polymer blends: A review on fundamental understanding. Macromolecular Materials and Engineering, 304, 1800431/1-1800431/33 (2019).

https://doi.org/10.1002/mame.201800431

[59] Parameswaranpillai J., Siengchin S., George J. J., Jose S.: Shape memory polymers, blends and composites. Springer, Berlin (2019).

[60] Lee K. S., Chang Y-W.: Thermal and mechanical properties of poly( $\varepsilon$-caprolactone)/polyhedral oligomeric silsesquioxane nanocomposites. Polymer International, 62, 64-70 (2013). https://doi.org/10.1002/pi.4309

[61] Khosravi A., Fereidoon A., Khorasani M. M., Naderi G., Ganjali M. R., Zarrintaj P., Saeb M. R., Gutiérrez T. J.: Soft and hard sections from cellulose-reinforced poly (lactic acid)-based food packaging films: A critical review. Food Packaging and Shelf Life, 23, 100429/1100429/17 (2020). https://doi.org/10.1016/j.fpsl.2019.100429

[62] Yu Z., Wang Z., Li H., Teng J., Xu L.: Shape memory epoxy polymer (SMEP) composite mechanical properties enhanced by introducing graphene oxide (GO) into the matrix. Materials, 12, 1107/1-1107/18 (2019). https://doi.org/10.3390/ma12071107

[63] Vanneste M., Groeninckx G.: Ternary blends of PCL, SAN15 and SMA14: Miscibility, crystallization and melting behaviour, and semicrystalline morphology. Polymer, 36, 4253-4261 (1995). https://doi.org/10.1016/0032-3861(95)92221-Y

[64] Zhu G., Xu S., Wang J., Zhang L.: Shape memory behaviour of radiation-crosslinked PCL/PMVS blends. Radiation Physics and Chemistry, 75, 443-448 (2006). https://doi.org/10.1016/j.radphyschem.2005.10.004

[65] Peponi L., Navarro-Baena I., Sonseca A., Gimenez E., Marcos-Fernandez A., Kenny J. M.: Synthesis and characterization of PCL-PLLA polyurethane with shape memory behavior. European Polymer Journal, 49, 893903 (2013).

https://doi.org/10.1016/j.eurpolymj.2012.11.001 
[66] Rezanejad S., Kokabi M.: Shape memory and mechanical properties of cross-linked polyethylene/clay nanocomposites. European Polymer Journal, 43, 2856-2865 (2007).

https://doi.org/10.1016/j.eurpolymj.2007.04.031

[67] Qi X., Yang G., Jing M., Fu Q., Chiu F-C.: Microfibrillated cellulose-reinforced bio-based poly(propylene carbonate) with dual shape memory and self-healing properties. Journal of Materials Chemistry A, 2, 20393 20401 (2014).

https://doi.org/10.1039/C4TA04954C

[68] Gu S-Y., Jin S-P., Liu L-L.: Polyurethane/polyhedral oligomeric silsesquioxane shape memory nanocomposites with low trigger temperature and quick response. Journal of Polymer Research, 22, 142/1-142/9 (2015). https://doi.org/10.1007/s10965-015-0779-2

[69] Lai S-M., Lan Y-C.: Shape memory properties of meltblended polylactic acid (PLA)/thermoplastic polyurethane (TPU) bio-based blends. Journal of Polymer Research, 20, 140/1-140/8 (2013).

https://doi.org/10.1007/s10965-013-0140-6

[70] Kashif M., Yun B-M., Lee K-S., Chang Y-W.: Biodegradable shape-memory poly(e-caprolactone)/polyhedral oligomeric silsequioxane nanocomposites: Sustained drug release and hydrolytic degradation. Material Letters, 166, 125-128 (2016).

https://doi.org/10.1016/j.matlet.2015.12.051
[71] Xu X., Fan P., Ren J., Cheng Y., Ren J., Zhao J., Song R.: Self-healing thermoplastic polyurethane (TPU)/polycaprolactone (PCL) /multi-wall carbon nanotubes (MWCNTs) blend as shape-memory composites. Composites Science and Technology, 168, 255-262 (2018). https://doi.org/10.1016/j.compscitech.2018.10.003

[72] Jiang G., Zhao N., Zhang S., Wang X.: Thermal, mechanical properties and rheological behavior of poly (propylene carbonate)/poly(ethylene glycol)/graphene oxide nanocomposites. Journal of Polymers and the Environment, 27, 2201-2212 (2019).

https://doi.org/10.1007/s10924-019-01509-9

[73] Agarwal S., Speyerer C.: Degradable blends of semicrystalline and amorphous branched poly(caprolactone): Effect of microstructure on blend properties. Polymer, 51, 1024-1032 (2010). https://doi.org/10.1016/j.polymer.2010.01.020

[74] Han D., Chen G., Xiao M., Wang S., Chen S., Peng X., Meng Y.: Biodegradable and toughened composite of poly(propylene carbonate)/thermoplastic polyurethane (PPC/TPU): Effect of hydrogen bonding. International Journal of Molecular Sciences, 19, 2032/1-2032/12 (2018). https://doi.org/10.3390/ijms19072032

[75] Dintcheva N. T., Morici E., Arrigo R., La Mantia F. P., Malatesta V., Schwab J. J.: Structure-properties relationships of polyhedral oligomericsilsesquioxane (POSS) filled PS nanocomposites. Express Polymer Letters, 6, 561-571 (2012).

https://doi.org/10.3144/expresspolymlett.2012.59 